\title{
Using Lexical Chunks for Developing MUST English Majors' Oral Communication
}

\section{Dr. Hanan Abdel-Baqi Mohammad Khalil}

Lecturer of Applied Linguistics (Methods of TEFL), Col. of FL Misr University for Science \& Technology (MUST)

\section{Abstract}

7 he current study investigated the effect of the training on using the lexical chunks on developing oral communication among 3rd year English majors at Misr University for Science and Technology (MUST). The problem of the study was that 3rd year English majors could not communicate effectively in oral interaction because of the lack of their awareness of the lexical chunks and how to apply them to have an effective oral communication. So, raising the degree of the study group's awareness of the lexical chunks, their forms, and how to apply them into real oral communication among 3rd year English majors in Summer 2016 semester. The study included some instruments, a pre lexical chunks oral test, an oral communication test, and a reflection sheet. Results of the lexical chunks oral test before the implementation of the study revealed that the study group did not receive any kind of direct or indirect instruction on using lexical chunks. Results of the pre/ post oral communication test proved that the study group could apply lexical chunks effectively in the oral communication test.

Keywords: (Lexical chunks, English idioms, collocations, phrasal verbs, oral communication)

\section{Introduction}

Language is sequential. Speech is a sequence of sounds. Writing is a sequence of symbols. Learning to understand a language involves dividing/analysing the speech stream into chunks which explicitly mark meaning. EFL learners care about grammar or whether words or morphemes are the smallest units of language. From the functional perspective, the role of language is to communicate meaning, and EFL leaner wants to acquire the accepted meaning relations. Learning how to communicate in English can be made easier by learning patterns of language, or what is called chunks of language. (Ellis, 1997) 
Tang (2013) explained that chunks are important components that can help in learning a foreign language. EFL learners should focus their attention on the use and functions of chunks and master them by adopting appropriate chunk acquisition strategies. EFL instructors should also be aware of the importance of the lexical approach in helping their learners enhance their language application abilities. The acquisition of chunks can be helpful for EFL learners improve their of speaking, writing, and reading. Accumulation of chunks could be an essential skill to FL and SL learners.

So, Lewis (1993) stated that grammatical mastery is not required for effective communication, any vocabulary- centred syllabus has to be organized around lexis rather than grammar and he concluded that lexis is the basis of language.

Schmitt (2000) and Moon (1997) explained that there is a good psycholinguistic basis for believing that the mind stores and processes the lexical chunks as individual wholes. The main reason stems from the structure of the mind itself. It can not only store enormous amounts of knowledge in the long term memory, but it is also able to process small amounts of it in real- time, such as when one is speaking. Actually, the mind makes use of relatively the rich resource (long-term memory) to compensate for the relative lack in another (processing capacity) by storing a number of frequently- needed lexical chunks as individual whole units. These can be easily retrieved and used without the need for composing them on -line through word selection and grammatical sequencing. This means that there is less demand on cognitive capacity, because the lexical chunks are "ready to go", and require little or no additional processing.

Schmitt (2000) commented that regular approaches have long dealt with multi-word units, where there is a single meaning related to more than one word, for example phrasal verbs (e.g. give up) compounds ( e.g. freeze dry), and idioms ( e.g. born with a silver spoon on one's mouth) . Nowadays, corpus- based research has proved that collocation extends beyond the level of such multi- word units. Lexical chunks are so common and are 
directly related to functional language use. They carry out language functions. Their function is to facilitate clear, relevant, and concise language use. So, the awareness of lexical chunks, and their different types is essential for oral language competence.

Schmitt (2000) added that lexical chunks play a significant role in facilitating language production and performed lexical chunks allow greater fluency in speech production. Lexical chunks include collocations, fixed, and semi-fixed expressions, phrasal verbs, and English idioms. EFL learners have to understand lexis as unanalysed wholes or chunks, without dividing them to their component parts.

Language activities used in an EFL classroom are usually directed toward naturally occurring language and the lecturer's main concern aims primarily at raising the learners' awareness of using the lexical chunks rather than the separate isolated words. Schmitt (2000) added that lexical chunks also play an important role in the acquisition of vocabulary and grammar.

Lewis (1997) and Moudraia (2000) introduced a taxonomy of lexical terms which included: a) Words such as book; pen; poly words such as by the way; upside down; b) collocations, such as natural resources, academic research; c) institutionalized utterances, such as I'll get it; d) sentence frames and heads, e.g. The danger was; e) text frames, such as Firstly, f) phrasal verbs, such as take-off; and go out) English idioms e.g. It was raining cats and dogs.

In the lexical approach, Lewis (1993:195) suggested what he called "Pedagogical chunking to be a frequent classroom activity, as students need to develop awareness of language to which they are exposed and gradually develop ways, not of assembling parts into wholes, but of identifying constituent bits within the whole"

Wray (2002) explained that if EFL learners of English could master a large number of chunks, it would be much helpful for them to understand what the speakers of English say, in other 
words, it could lead to effective oral communication. When EFL learners do not have the sufficient awareness of how to use lexical chunks efficiently, this could lead to difficulty and deficiency in the pre-lexical chunks oral test.

\section{The Pilot Study}

It contained: 1) a structured interview and 2) à pre -lexical chunks oral test. The structured interview and the test on using lexical chunks with the study group of $3^{\text {rd }}$ year English majors at MUST in summer 2016, revealed the following results:

- Most of the students explained that they did not receive any kind of direct or indirect instruction or training on lexical chunks.

- Many students in the lexical chunks test and the structured interview could not differentiate between collocations and idiomatic expressions usage.

- About $85 \%$ of the English majors did not know what the term "Lexical chunks" means or what their types are.

- About $70 \%$ of the English majors were not sure that they can communicate effectively in English because they could not find the correct words or expressions that could convey the meaning they want to express.

- Most of them explained that they could not recognize the type of lexical chunks used in the spoken input given to them in listening or speaking.

\section{Context of the Problem}

Most of $3^{\text {rd }}$ English majors at MUST have a little chance for oral communication in English. They are also unaware of the lexical chunks included. An essential part of the course "Study skills" is a unit entitled "learning through oral communication and discussion", which is usually neglected and not taught because of the limited time of the course especially during the summer semester. Also, English majors attempted to avoid oral communication because of the lack of awareness of what appropriate expressions and phrases that should be used to 
express themselves. So, an enrichment activity based on training on lexical chunks was suggested to encourage them to participate in oral communication.

\section{Statement of the Problem}

The problem of the current research was that $3^{\text {rd }}$ year English majors could not communicate accurately and fluently because of the lack of their awareness of the lexical chunks that were not taught to them before. The current study aimed at developing English majors' oral communication through raising the students' awareness of using lexical chunks.

\section{Research Questions}

The current research attempted to answer the following questions:

1. How far do MUST English Majors master oral communication skills?

2. To what extent is training on lexical chunks effective in developing the overall oral communication skills?

3. What is the effect of the training on using lexical chunks on developing each type of the communication among $3^{\text {rd }}$ English majors at MUST?

\section{Research Hypotheses}

1. There is a statistically significant difference between the mean scores of the study group in the overall oral communication pre/ post-test in favour of the post.

2. There is a statistically significant difference between the study group's mean scores in each component of the three overall types of the oral communication test in the pre/ post test in favour of the post.

3. Training on lexical chunks is effective in developing oral communication among $3^{\text {rd }}$ year English majors.

\section{Delimitations of the Study}

This study is delimited to:

1. A group of (31) $3^{\text {rd }}$ year English majors who were enrolled in the course" Study Skills" in summer semester, 2016. 
2. Only three types of lexical chunks; collocations, idioms, and phrasal verbs.

\section{Review of Literature}

Vocabulary has usually been looked at as individual words, but it is important to mention that lexis consists of sequences of words which operate as individual units, with a meaning which is different from isolated words in language learning. (Tang, 2013)

This type of sequence of words is called "Lexical chunks" which is defined by Wray (2002) as a sequence, continuous or discontinuous, of words or other elements, which is stored and retrieved whole from memory at the time of use, rather than being subject to generation or analysis by the language grammar.

Therefore, if EFL learners could master a large number of chunks, they would be able to analyze the meanings of what the speakers say. Lewis (1997) pointed out that lexical chunks include collocations, fixed and semi- fixed expressions, and idioms. They can be classified as:

- Poly words (e.g. by mean of, in this way, upside down...etc)

- Collocations and idioms (e.g. qualitative research; it was raining cats and dogs, etc)

- Institutionalized utterances (e.g. It's beyond me; would you like a cup of coffee? etc....

- Sentence frames and heads (Some believe that...; the primary reason is that etc)

- Phrasal verbs (take off, look after, etc)

\section{Lexical Approach and Language learning}

Lewis $(1993 ; 1997 ; 2000)$ mentioned that the "Lexical approach" based on theory of chunks refers to the idea or belief that building blocks of language learning and communication are not only grammar, functions, notions, or some other units of planning and teaching but lexis, that is words and word combinations. He continued that vocabulary learning and lexical 
chunks are considered the central part and basis of learning and teaching EFL or ESL in the lexical approach. Lewis (1997) emphasized that any language consists of grammaticalized lexis, not lexicalized grammar. He explained that the lexical approach argues that the majority of spoken sentences are not newly created and that lexical chunks form the multi- units or memorized patterns and contribute to the formation of fluent expressions heard in everyday conversations. Lexical chunks can efficiently accelerate the speed of processing and generating language. Lewis (1997) argued that the Lexical approach is the supplement and advancement of the communicative approach.

Lewis (1997) also introduced some activities based on lexical chunks to develop oral communication and fluency EFL examples are:

- Intensive and extensive listening and reading in English as a FL.

- Using repetition and recycling activities to keep the learnt lexical chunks active.

- Guessing the meaning of the lexical chunks from context.

- Training the EFL students on how to elicit the words, fixed expressions, collocations, and English idioms from context.

\section{The Relation of Training on Lexical Chunks to Listening Competency}

Tang (2013) investigated the effectiveness of learning and training on using lexical chunks to improve EFL learners' listening competency. The empirical study based on the chunks theory was designed and conducted. Analysis of the experimental data showed that the acquisition of chunks was effective in improving the study group's listening competency. It also revealed that the number of chunks is closely correlated with the EFL learners' listening scores as the chunks enhanced the Fl learners' efficiency of processing language information. 
Tang (2013) emphasized the fact that an essential learning strategy is to teach and train EFL students to recognize and to be aware of the chunks when they are exposed to the listening discourse. He suggested that the accepted way is to play tapes repeatedly and focus too much on requiring students to fix their attention on separate syllables, words and sentences. After being able to identify chunks, students should be trained and guided to raise their awareness of using chunks and learn how to focus their attention during the listening comprehension on the combination of chunks with the context.

Communicating in English as a foreign language not only depends but on knowing the meaning of a word which is of course useful, but knowing how to use it in context as well. That is because words are not used in isolation and they usually form parts of expressions or a fixed group of words. To be aware of those chunks of vocabulary and to know how to use them in oral communication can help EFL learners to improve their English fluency skills. (Jamshidnejad (2011); Kaur (2008); Ya-Ni (2007); Swaim and Lapkin (2002); Swaim (2000); Foster and Ohta (2005).

\section{English Idioms, Collocations, and Phrasal Verbs}

English idioms are used frequently in everyday situations, and therefore they need to be considered and used by teachers and lecturers in EFL classes. So, the training of EFL learners on using English idioms as lexical chunks has to go beyond the simple word-by- word comprehension strategy and integrating figurative meaning idioms are very common in both written and spoken language (Alrishan(2015); Chen\& Lai( 2013); Pimenova (2011); Bagheri\& Fazel (2010); Boers (2008); Brown (2001); Nunan (2003); Burke, 1998). Examples of some English idioms are, e.g. Raining cats and dogs; Born with a silver spoon in one's mouth; Plain as the nose on one's face. Since idioms are part of the language system, students should learn them in order to be fluent in the target language (Burke, 1998). Lundblum and Woods (2012) explained that idioms are commonly used in both written and spoken language. They appear in conversations, magazines, newspapers, and media. 
Su-Yueh (2008) introduced some strategies for teaching idioms; one of them is to teach idioms with group discussion. He explained that EFL students' discussion about what they read is a helpful strategy to increase their comprehension. The use of English idioms in group discussion can provide learners with rich opportunities to acquire social and linguistic knowledge.

Native-like selection of lexical chunks in oral communication is not a matter of syntactic rule alone. Nativelike speaking is speaking idiomatically using frequent familiar collocations. Collocations are one of the areas that produce problems for EFL learners. It is a significant part of EFL learners' problems with producing the language. It is defined as a multiword expression including an important component of fluent linguistic production (Sadeghi, 2009). Collocations are words that usually occur together and the EFL learner has to learn these familiar word combinations or sequences together. Native speakers use frequent and familiar collocations in their conversational speech which are considered as "fluent units" or collocations, e.g. an alarming degree, qualitative research, research methods, potential problem, principal cause, apparent discrepancy, rigorous methodology (Ellis, 1997).

Phrasal verbs occur most frequently in more informal spoken and written English They are mostly used in academic contexts or assignments such as go/ look back over; work out; carry out; make up, point out; set out. The verb plus a preposition form the phrasal verbs. Each phrasal verb has a completely different meaning from the base verb, e.g. "carry out' meaning "conduct" has a completely different meaning from the verb carry. Phrasal verbs often have one-word synonyms. These are usually of Latin origin and sound more formal than their phrasal verb equivalent but both are appropriate when writing or talking about academic subjects.

\section{Method}

\section{Participants of the Study}

The participants in this study included (31) $3^{\text {rd }}$ year English majors at Misr University for Science \& Technology (MUST), 
Egypt. The study included only one study group who registered in the "Study Skills in English" course, coded as Lang 120,in Summer 2016 . The researcher used a pre/ post quasiexperimental design.

\section{Instruments of the Study}

The current study used 1) a pre/ post oral communication test, and 2) a post-reflection sheet.

The oral communication test was designed and implemented before and after the enrichment activity to obtain the quantitative data. The test included about five situations in which the study group had to communicate with each other orally using English idioms, collocations, and phrasal verbs.

\section{The Oral Communication Test}

\section{Aim of the Test}

The oral communication test was designed and implemented before and after the intervention to obtain the quantitative data. It was used before the intervention to measure the participants' entry level before the intervention. As a posttest, it was used to investigate the effectiveness of the training sessions.

It consisted of 6 questions, and each question included 5 items. The $1^{\text {st } ~ \& ~ 2 n d ~ q u e s t i o n s ~ a s k e d ~ t h e ~ s t u d e n t s ~ t o ~ u s e ~}$ collocations to speak about writing an academic MA proposal. The $3^{\text {rd }} \& 4^{\text {th }}$ questions asked the students to use idioms to speak about lifestyle and the weather. The $5^{\text {th }} \& 6^{\text {th }}$ questions asked the students to use a number of phrasal verbs to speak about conducting an academic research. Appendix (2)

\section{Validity of the Oral Communication Test}

To ensure the validity of the reading efficiency test, the initial version of the test was

presented to a panel of jury members. Their comments on the test were considered. The final version of the test included three main sections, concentrating mainly on the usage of the three targeted lexical chunks; English idioms, collocations, and 
phrasal verbs in oral communication. The jury suggested the oral communication situations to be audio or video recorded. The researcher considered their suggestions.

The $1^{\text {st }}$ three training sessions were and the oral test were audio- recorded. Each student was asked to use all of the three types of the lexical chunks in real oral test of communication.

\section{Reliability of the Oral Communication Test}

The final version of the test was administered to (32) 3rd year English majors at MUST rather than those participating in the study. Cronback Alpha was used to measure the reliability coefficient of the test. The calculated coefficient was 0.87 . So, the oral communication test proved to be reliable in assessing the students' use of lexical chunks to develop their oral communication.

\section{The Reflection Sheet}

\section{Aim}

The reflection sheet was administered after the intervention to obtain qualitative data about the study group's reflections to using the lexical chunks to improve the quality of their oral communication.

\section{Description}

The reflection sheet concentrated primarily on five main aspects such as: the content of the manual, the methodology, the lecturer, techniques used, and the evaluation methods.

The study group were asked to write their reflections on the training activity based on using lexical chunks for developing oral communication.

\section{Validity}

To ensure the validity of the reflection sheet, the initial version of the sheet was given to a panel of jury members. Their comments on the reflection sheet were considered. The final version of the sheet included five main sections, concentrating mainly on the students' reflections on the training activity. The 
jury suggested the adding a extra section on evaluation. The researcher considered their suggestions.

This instrument was administered after the implementation of the enrichment activity. The purpose of using this instrument was to collect some information about the participants' reflections towards the content, methodology used, the lecturer, teaching techniques, the activities included, and the evaluation of the enrichment activity.

\section{The Manual}

\section{Aim}

The manual of the training activity aimed mainly at giving a comprehensive description of the activities included in the training on using lexical chunks to develop oral communication.

\section{Objectives}

The major objectives of the current study were to:

- Develop the quality of the oral communication among $3^{\text {rd }}$ year English majors at MUST by training on using an enrichment activity based on lexical chunks.

- Raise the degree of awareness of the lexical chunks, its types, importance, among the study group through the $1^{\text {st }}$ two lectures of the activity.

- The researcher attempted to guide the participants of the study to utilize their knowledge of the lexical chunks, and the target three types of lexical chunks During their oral communication in class aiming at developing the quality of the contexts they use in their oral communication skill.

- The four main sessions of the enrichment activity are included in Appendix (3).

\section{Content of the sessions}

The enrichment activity included six sessions. The $1^{\text {st }}$ three sessions discussed mainly the collocations, their forms, and how they can be used in oral communication. The $2^{\text {nd }}$ session discussed the English idioms, their function in the English 
language, and giving a number of English idioms, the can be used in oral communication. The $3^{\text {rd }}$ session explained the phrasal verbs, their formation, their synonyms, and how can the EFL students utilize them in oral communication. The following three sessions contained a training on using the three overall lexical chunks in real situations discussing different topics, such as " Do women drive better than men?", " Tips to be followed to carry out an academic research", and "the reasons that cause being late to attend the lectures".

\section{Evaluation}

- At the end of every session, the study group were asked some questions related to the content of the session to help them be aware of the three target types of lexical chunks.

- The three later sessions emphasized mainly on the study group's actual usage of the three types of lexical chunks in oral communication. The students were divided into groups. Each group had to practise using collocations, idioms, and phrasal verbs in the suggested topics.

\section{The Treatment}

\section{a) Pre-testing}

Before the treatment, the study group were given both a structured interview, an oral lexical chunks test, and a pre-oral communication test.

\section{b) Treatment}

Reference to the sessions, and the steps followed while teaching lexical chunks, every session followed these procedures: An Example session:Lexical Chunks, Importance, and Types

\section{Objectives of the session}

- By the end of this session, English majors will be able to:

- Define the term "lexical chunks" correctly.

- Mention some of the types of lexical chunks

- write at least three examples for each type of the lexical chunks. 


\section{Warm up}

The researcher asked some open-ended questions related to the contents of the session to arouse the participants' attention, and to help them to raise their awareness of the tool.

\section{Briefing (Explicit instruction)}

The researcher started by providing a short introduction to lexical chunks. She explained that language is sequential and that speech is a sequence of sounds. Writing is a sequence of symbols. Learning to understand a language involves dividing/analysing the speech stream into chunks, which are called "lexical chunks". Then, the researcher gave them some of the types of lexical chunks that are used in the English language and used commonly by native speakers in their everyday language, conversations, and oral communication activities.

\section{Practice}

At first, the researcher guided the participants to practise lexical chunks in conversations and communication. Then, independently converted oral communication using lexical chunks. The researcher guided the participants making conversations, communicating, and helping them making use of the lexical chunks and items presented. The researcher asked the study group to use some of the commonly used collocations in a simple conversation. The researcher explained to the students how to use some collocations in real situations. Then, in groups the participants independently used other collocations in oral communication situations.

\section{Evaluation}

By the end of the session, the participants were divided into about five groups. Each group was asked to choose one topic through which they can use some of the collocations that were discussed before in the briefing stage.

\section{c) Post-testing}

After the implementation of the enrichment activity based on using lexical chunks to develop oral communication among English majors, both a post oral communication test and a 
reflection sheet were administered to the participants in the study.

\section{Results and Discussion}

The researcher used SPSS version 22 to verify the study hypotheses.

Hypothesis one stated that " There is a statistically significant difference between the mean scores of the study group in the overall oral communication skills pre/ post-test in favour of the post". Data were treated statistically and the findings are shown in the following table.

Table (1) The Study Group's mean scores in the Overall Oral Communication pre/post Test and its three main parts.

\begin{tabular}{|c|c|c|c|c|c|c|c|c|c|c|}
\hline \multirow{2}{*}{$\begin{array}{l}\text { Lexical } \\
\text { Chunk }\end{array}$} & \multirow[t]{2}{*}{ Administration } & \multirow[t]{2}{*}{$\mathrm{N}$} & \multirow[t]{2}{*}{ M } & \multirow[t]{2}{*}{ S.D } & \multicolumn{2}{|c|}{$\begin{array}{c}\text { Paired } \\
\text { differences }\end{array}$} & \multirow[t]{2}{*}{ D.F } & \multirow{2}{*}{$\begin{array}{c}\text { 't' } \\
\text { value }\end{array}$} & \multirow{2}{*}{$\begin{array}{l}\text { Level } \\
\text { of sig. }\end{array}$} & \multirow{2}{*}{$\begin{array}{l}\text { Effect } \\
\text { size }\end{array}$} \\
\hline & & & & & $\mathrm{M}$ & $\mathrm{s}$ & & & & \\
\hline \multirow{2}{*}{ Idioms } & post & 32 & 16.25 & 4.846 & \multirow[t]{2}{*}{10.875} & \multirow[t]{2}{*}{4.233} & \multirow{2}{*}{31} & \multirow{2}{*}{14.533} & \multirow{2}{*}{\begin{tabular}{|c|} 
Sig. at \\
0.05
\end{tabular}} & \multirow{2}{*}{5.22} \\
\hline & & 32 & 5.38 & 1.699 & & & & & & \\
\hline \multirow{2}{*}{$\begin{array}{c}\text { Phrasal } \\
\text { verbs }\end{array}$} & post & 32 & 7.94 & 2.213 & \multirow[t]{2}{*}{3.812} & \multirow[t]{2}{*}{2.023} & \multirow{2}{*}{31} & \multirow{2}{*}{10.661} & \multirow{2}{*}{\begin{tabular}{|c|} 
Sig. at \\
0.05 \\
\end{tabular}} & \multirow{2}{*}{3.83} \\
\hline & pre & 32 & 4.12 & 1.454 & & & & & & \\
\hline \multirow{2}{*}{ Collocations } & post & 32 & 12.09 & 1.692 & \multirow[t]{2}{*}{8.062} & \multirow[t]{2}{*}{1.813} & \multirow{2}{*}{31} & \multirow{2}{*}{25.159} & Sig. at & \multirow[t]{2}{*}{9.04} \\
\hline & pre & 32 & 4.03 & 1.656 & & & & & 0.05 & \\
\hline \multirow{2}{*}{ Total } & post & 32 & 36.28 & 6.854 & \multirow{2}{*}{22.750} & \multirow{2}{*}{4.508} & \multirow{2}{*}{31} & \multirow{2}{*}{28.547} & Sig. at & \multirow{2}{*}{10.25} \\
\hline & pre & 32 & 13.53 & 3.818 & & & & & 0.05 & \\
\hline
\end{tabular}

Table (1) indicates that there were statistically significant differences at 0.05 level in using the lexical Chunks in the oral communication and its three parts; idioms, phrasal verbs, and collocations between the mean scores of the study group in the pre / post-test in favor of the post-test, since the estimated tvalues were (14.533), (10.661) and (25.159). Respectively $t$ value of the overall communication skills (its components) was (28.547). Furthermore, the calculated effect size values were $(5.22),(3.83),(9.04)$ and $(10.25)$ for the first, the second, and the third components of the test and the overall score of the oral communication test. This reflects that the manual based on using the lexical chunks was effective on developing the oral communication skills among the students of the group Thus, the first hypothesis was verified. 
Hypothesis Two stated that "There is a statistically significant difference between the study group's mean scores in each component of the three overall types of the oral communication test in the pre/ post-test in favour of the post"

The researcher used Black's equation for modified gain score to test the effectiveness of the enrichment activity for developing the quality of oral communication among English majors at MUST.

Table (2). The Effectiveness of the Enrichment Activity based on Lexical Chunks for Developing Oral Communication among the study group

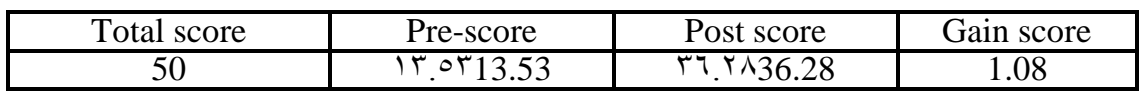

The results show that the gain score is approximately 1.1 and it is near from 1.2 which represent that using the training on Lexical chunk proved to be effectiveness in developing the quality of oral communication among the study group.

Hypothesis (3) " Training on lexical chunks is effective in developing oral communication among $3^{\text {rd }}$ year English majors"

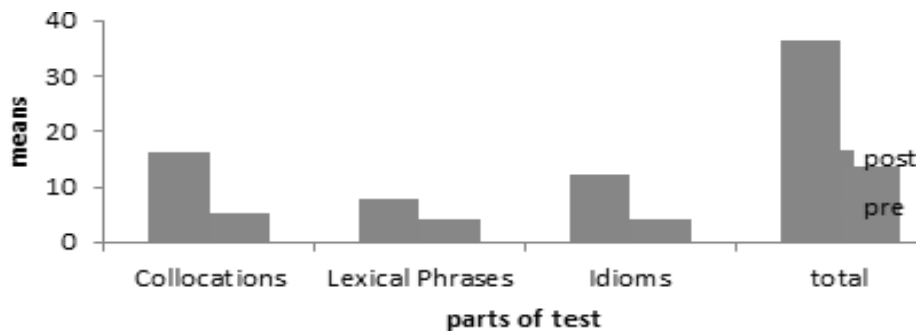

Figure (1) shows the differences among the study group in the gain ratio of the three target types of lexical chunks (collocations, idioms, and phrasal verbs). From the figure it is clear that the study group's development in both collocations and idioms was better than their development in using the phrasal verbs in oral communication.

\section{Results of the Reflection Sheet}

The reflection sheet's results showed that the study group had a positive attitude towards the use of the manual in 
developing communication skills enrichment activity. They were satisfied with the content, methodology, the teaching techniques used, e.g. working in oral communication groups. They explained that they could benefit a lot of using lexical chunks which they did not receive any direct or indirect instruction on using them before. They reported that they could recognize that storing the lexis they learn in chunks is better than learning them in isolation which may lead to forgetting them. Most of the participants reported that even the evaluation of the activity was interesting because they used to work together through the oral communication. One of them reported that she is no longer shy to speak in front of her colleagues because she herself constituted a part of a team working together.

\section{Discussion}

The results of the oral communication pre/ post-test, and the reflection sheet proved that using lexical chunks was effective in developing oral communication among the study group. Using the lexical chunks helped to improve the participants' long-term memory in storing the lexis they study and use speaking and in oral communication skills.

Results of the reflection sheet showed that it is not the matter of keeping a lot of vocabulary in their minds, but what is more important is how to learn to store, use, and recall them actually when communicating with each other orally. The students could employ the three target lexical chunks successfully in their oral communication. The study group could also differentiate successfully the three types of lexical chunks, when, why, and how to use them in real situations. They could be able to realize that oral communication is not only using any vocabulary they have learnt before in oral communication, but the most important aspect is the quality itself they could use to enhance their oral communication skill. They became aware that using collocations, English idioms, and phrasal verbs in their oral communication help them to be creative and distinguished.

Another result was that the study group developed their oral communication when using both collocations and idioms 
better than using phrasal verbs. The reason beyond this result was that phrasal verbs are used commonly in written assignments rather than in oral communication. So, results of the current study were consistent with other studies Such as Tang (2013); Lewis (2000); Ellis (1997).

\section{Conclusions and Recommendations}

This study attempted to develop the quality of oral communication among $3^{\text {rd }}$ year English majors at Misr University for Science and Technology (MUST), in Egypt through training on using lexical chunks. The findings of the present study had significant implications for EFL learners, lecturers, researchers in the field of TEFL. Teaching assistants, lecturers, and instructors are advised to use lexical chunks and not isolated separate words. They are also recommended to attempt to raise their students' awareness of learning the different types of lexical chunks and how to use them in their real oral discussions or conversations.

This study proved evidence for the benefits of training on the different types of lexical chunks.

Most of the EFL learners who had problems with oral communication could benefit from the current study through verifying the teaching techniques in class such as dividing them into groups during practicing the oral communication skill. This had a positive impact on their attitudes in general and on their oral communication particularly.

English majors' reflections showed that the direct instruction on using the lexical chunks was effective rather than the indirect type of instruction. It helped in raising the

Study group's awareness of the importance to work in groups and to communicate with each other using the appropriate lexical chunks that can help better in every situation.

\section{Suggestions for Further Research}

- Further studies can be conducted in other types of lexical chunks, e.g. Institutionalized phrases, poly words, lexical phrases, etc. 
- Carrying out other researches based on using other language skills, i.e. writing, reading, listening, or speaking.

- Conducting a comparative study on gender effect in oral communication skills.

- Carrying out a study on training both preparatory and secondary school students on using lexis as lexical chunks rather than teaching them vocabulary in isolation in the form of vocabulary lists.

- A study could be conducted on using mind and concept maps and concept for teaching both reading and writing.

\section{References}

Alrishan, A. (2015). The Perceptions of EFL Jordanian University Instructors of the Process of Teaching/ Learning the Translation of Idioms. International Journal of Social Science Studies. (6), Nov. 2015.

Bagheri, M. \& Fazel, I. (2010). Effects of Etymological Elaboration on EFL Learners' Comprehension and Retention of Idioms, Applied Linguistics, 14, 454-55.

Boers, F. (2008). Language Awareness: Understanding Idioms. MED Magazine, 49-1-4.

Brown, H. (2001). Teaching by Principles: An Interactive Approach to Language Pedagogy. 2ndEdition. White Plains, New York: Pearson Education.

Burke, D. (1998). Without Slang and Idioms, Students are in "In the Dark", ESL Magazine, 1(5), 20-23.

Chen, Y. (2013). Teaching English Idioms as Metaphors through Cognitive-Oriented Methods: A case in an EFL Writing Class, English Language Teaching, 6(6), 13-20.

Ellis, N. (1997) Vocabulary Acquisition: Word Structure, Collocation, Grammar, and Meaning. In McCarthy\& Schmidt (Eds.) (1997), Vocabulary: description, acquisition and Pedagogy. Cambridge: Cambridge University Press.

Foster, P.\& Ohta, A. (2005). Negotiation for Meaning and Peer Assistance in Second Language Classrooms. Applied Linguistics, 26(3), 402-430. 
Jamshidnejad, A. (2011). Developing Accuracy by Using Oral Communication Strategies in EFL Interactions. Journal of Language Teaching and Research, 1, 3, pp. 530-546, May 2011.

Kaur, J. (2008). Doing Being a Language Expert: The Case of the EFL Speaker. The Second International Conference of English as a Lingua Franca, Southampton, England.

Lewis, M. (1993). The Lexical Approach: The State of ELT and the Way Forward. Hove, England: Language Teaching Publications.

Lewis, M. (1997a). Implementing the Lexical Approach: Putting Theory into Practice. Hove, England: Language Teaching Publications.

Lewis, M. (1997b). Pedagogical Implications of the Lexical Approach. Cambridge: Cambridge University Press.

Lewis, M. (2000). Language in the Lexical Approach. Hove, England: Language Teaching Publications.

Moon, R. (1997). Vocabulary Connections: Multi-word Items in English. Cambridge: Cambridge University Press.

Moudraia, 0. (2001). Lexical Approach to Second Language Teaching. Center for Applied Linguistics. (ERIC Digest, EDOFL-01-02)

Nunan, D. (2003). Practical English Language Teaching. New York: McGraw Hill.

Sadeghi, K. (2009). Collocational Differences between L1 and L2: Implications for EFL Learners and Teachers. TESOL Canada Journal, 26, 2, Spring 2009. - Tang, J. (2013). Input of Chunks and Its Effects on L2 Learners' Listening Competency. Theory and Practice Language Studies, 3, 7, pp. 1264-1269, July, 2013, Academy Publisher. ISSN 1792591

Schmitt, N. (2000). Key Concepts in ELT. ELT Journal, Vol. 54/4, Oct. Oxford University Press.

Su-Yueh, W. (2008). Effective Activities for Teaching English Idioms to EFL Learners. The Internet TESL Journal, 14, 3, March 2008 
Swain, M. (2000). The Output Hypothesis and beyond: Mediating Acquisition Through Collaborative Dialogue. Oxford: Oxford University Press.

Swain, M. \& Lapkin, S. (2002). Talking it Through: Two French Immersion Learners' Responses to Reformulation. International Journal of Educational Research, 37, 285-304.

Ya-Ni, Z. (2007). Communication Strategies and Their Significance in Foreign Language Teaching. US-China Foreign Language, 5(4), 43-47. 
